\section{FRI0729 DEFINITION OF REMISSION AND MINIMAL DISEASE ACTIVITY IN PSORIATIC ARTHRITIS: A SYSTEMATIC LITERATURE REVIEW}

T. Gudu ${ }^{1,1}$, R. Ionescu. Rheumatology, Sf Maria Hospital, UMF Carol Davila, Bucharest, Bucharest, Romania

Background: In psoriatic arthritis (PsA) a state of minimal disease activity (MDA) or remission are the target of treatment [1], but due to the heterogeneity of disease manifestations, it is still an unmet need. Coates et al [2] have developed and validated a composite score for MDA that encompasses most disease domains. However, for disease remission there is no accepted definition, with studies "borrowing" measures from rheumatoid arthritis or using their own criteria.

Objectives: The objective of this study was to analyse existing data on the definition of MDA and remission in studies on PsA.

Methods: A systematic literature review was performed. Studies evaluating remission or minimal disease activity in PsA either as a primary or secondary outcome, published between 2007-2017, were identified using the terms ("psoriatic arthritis") AND ("remission" OR "low disease state" OR "low disease activity" OR "minimal disease state" OR "minimal disease activity"). Studies assessing disease activity in general, without specifically mentioning remission or MDA were not included; reviews and case-reports were also excluded.

Results: Two hundred and thirty-five publications were identified, of which 56 were included in the final analysis. The majority were observational studies $(85.5 \%)$ and there were no qualitative studies identified. In total, 10843 PsA patients were analysed: 8779 in observational studies and 2064 in interventional studies; 4823 patients fulfilled the CASPAR criteria [3] and 6667 (31 studies) were taking a biologic drug at their inclusion. The majority of the studies assessed either MDA $(65.5 \%)$ or remission $(60 \%)$, but only 14 studies $(25.5 \%)$ assessed both of the two outcomes. MDA or remission were mainly used as a secondary outcome $(52.7 \%$ of the studies).

MDA was assessed mainly in observational studies (61.7\%) and in almost all cases $(88.9 \%$ of the studies) the definition used was the one proposed by Coates et al [2]. Remission was also assessed mainly in observational studies $(63.8 \%)$. The most used definition $(57.6 \%)$ was based on the disease activity score (DAS28), with values less than 2.6 considered as "remission". Articular involvement was assessed in all cases, whilst skin psoriasis, dactylitis and enthesites were rarely included in the definition of remission (15.15\% each). Physician's assessment was taken into consideration in almost a third of the studies $(27.3 \%)$, but the patient's assessment (pain or global evaluation) was included in more than half of the studies $(69.7 \%)$. However, other patient reported outcomes were sparsely used (i.e., fatigue and morning joint stiffness were included in only one study) or not all reported (e.g, social participation, work productivity, depression).

Conclusions: Whilst for MDA there is a standardised definition which is widely used, there is no accepted definition for remission. In defining remission, domains other than articular are seldom used and although patient's opinion is usually evaluated, it rarely includes domains other than pain or global assessment. The concept of remission remains un unmet need in PsA.

References:

[1] Gossec L, Smolen JS, Ramiro S, et al. Ann Rheum Dis 2016;75(3):499-510.

[2] Coates LC, Fransen J, Helliwell PS. Ann Rheum Dis 2010;69(1):48-53.

[3] Taylor W, Gladman D, Helliwell P, et al. Classification criteria for psoriatic arthritis: development of new criteria from a large international study. Arthritis Rheum 2006;54(8):2665-73.

Disclosure of Interest: None declared

DOI: 10.1136/annrheumdis-2017-eular.5813

\section{FRI0730 THE NEED FOR HOSPITAL ADMISSION FOR SYSTEMIC LUPUS ERYTHEMATOSUS IN WESTERN AUSTRALIA LEADS TO A DOUBLING OF THE ALL-CAUSE MORTALITY RISK AS SEEN IN CONTROLS, ESPECIALLY FOR MEDICARE RELIANT AND MALE PATIENTS}

W.D. Raymond ${ }^{1}$, D. Preen ${ }^{2}$, C. Inderjeeth ${ }^{1,3}$, H. Keen ${ }^{4,5}$, J. Nossent ${ }^{1,6} .{ }^{1}$ School of Medicine \& Pharmacology; ${ }^{2}$ School of Population Health, University of Western Australia; ${ }^{3}$ Rehabilitation and Aged Care, Sir Charles Gairdner Hospital; ${ }^{4}$ Rheumatology, Fiona Stanley Hospital; ${ }^{5}$ School of Medicine, Murdoch University; ${ }^{6}$ Rheumatology, Sir Charles Gairdner Hospital, Perth, Australia

Background: Hospitalisation for Systemic Lupus Erythematosus (SLE) is a significant event.

Objectives: We aimed to understand the factors leading to an incident admission and its impact on long term outcome in SLE patients in Western Australia (WA). Methods: Using whole-population data linkage of hospital admissions, cancer registrations and death records in WA from 1980 to 2015, we performed a retrospective comparative analysis for all patients admitted with a first ever primary diagnosis of SLE (ICD-9-CM 695.4, 710.0, ICD-10-AM L93.0 \& M32). For SLE patients, we analysed annual incident hospitalisation rates and compared patient characteristics, all-cause mortality and cancer risk (by Kaplan-Meier and Cox regression) versus age- and gender-matched controls free of rheumatic disease.

Results: The incident hospitalisation rate for SLE (mean 20.9/million/year (Cl: 11-35) showed little variation. SLE patients were younger, more likely to be
Indigenous, uninsured, have kidney and cardiovascular disorders and to die during their first hospitalisation (Table 1). Cancer risk was equivalent, but a first admission for SLE doubled the risk of subsequent death $(\mathrm{OR}=1.99, \mathrm{Cl}: 1.5-2.7$, $\mathrm{p}<0.001$ ) (Figure 1/Table 2). Medicare reliance (OR 1.7, Cl: $1.4-1.9, \mathrm{p}=0.001$ ) and male gender (OR 1.4, Cl: $1.0-1.8, p<0.04$ ) were the strongest independent predictors of death

Figure 1: Kaplan-Meier survival analysis of all-cause mortality for SLE patients and age- and sexmatched controls (free of rheumatic disease) from index hospitalisation.

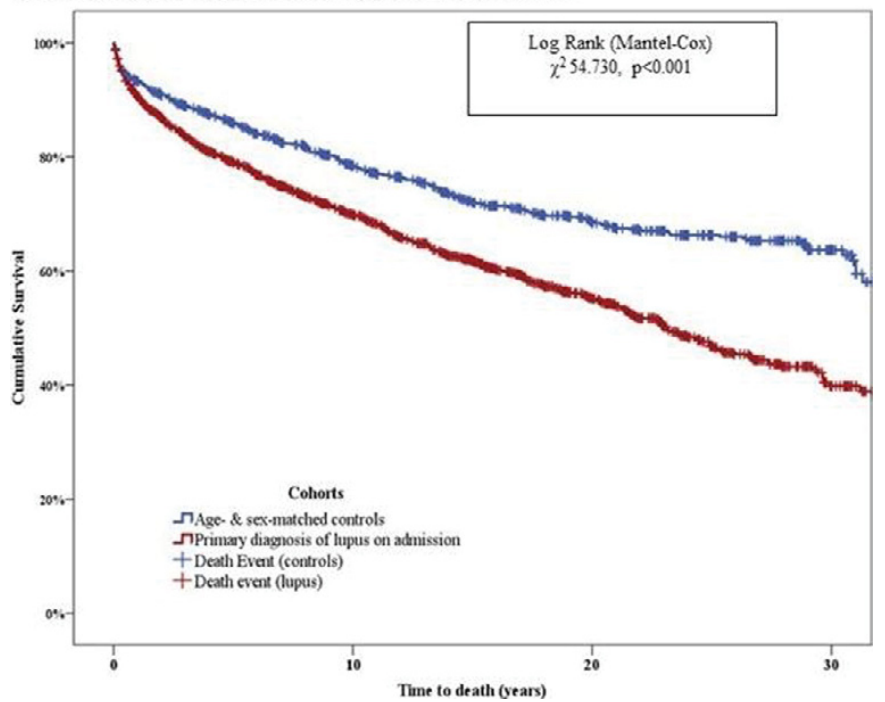

Conclusions: Hospitalisation rates for SLE in WA have not decreased over 25 years. Once hospital-based management for SLE was required, the risk of all-cause mortality doubled compared to age and gender-matched controls. This risk was greatest in Medicare reliant or male SLE patients and not due to increased cancer risk.

Disclosure of Interest: None declared

DOI: 10.1136/annrheumdis-2017-eular.5866

\section{FRI0731 ASSESSING THE RISK OF RAPID RADIOLOGIC PROGRESSION IN HUNGARIAN RHEUMATOID ARTHRITIS PATIENTS}

G. Szücs ${ }^{1}$, J. Gaál ${ }^{2}$, P. Géher ${ }^{3}$, E. Gömöri ${ }^{4}$, A. Kovács ${ }^{5}$, L. Kovács ${ }^{6}$, K. Nagy ${ }^{7}$, E. Posta ${ }^{8}$, L. Tamási ${ }^{9}$, E. Tóth ${ }^{10}$, E. Varga ${ }^{11}$, A. Domján ${ }^{1}$, Z. Szekanecz ${ }^{1}$. ${ }^{1}$ Department of Rheumatology, University of Debrecen, Faculty of Medicine,

${ }^{2}$ Department of Rheumatology, Kenézy County Hospital, Debrecen: ${ }^{3}$ Department of Rheumatology, Hospital of Hospitaller Brothers of St. John of God, Budapest; ${ }^{4}$ Department of Rheumatology, Pándy Hospital, Gyula; ${ }^{5}$ Department of

Rheumatology, Hospital of State Railways, Szolnok; ${ }^{6}$ Department of

Rheumatology, University of Szeged, Szeged; ${ }^{7}$ Department of Rheumatology, Ferenc Markhot Hospital, Eger; ${ }^{8}$ Department of Rheumatology, András Jósa Hospital, Nyiregyháza; ${ }^{9}$ Department of Rheumatology, Semmelweis Teaching Hospital, Miskolc; ${ }^{10}$ Department of Rheumatology, Ferenc Flór Hospital, Kistarcsa; ${ }^{11}$ Department of Rheumatology, Markusovszky Hospital, Szombathely, Hungary

Background: Prognosis of rheumatoid arthritis (RA) should be assessed early during the disease course. Rapid radiological progression (RRP) has been defined as a $>\%$ unit increase in van der Heijde-Sharp score within a year. The matrix risk model has been developed by Vastesaeger et al in 2009. This tool calculates RRP based on non-radiographic indicators such as baseline CRP, RF and swollen joint count.

Objectives: We wished to test the matrix prediction model int he very first Hungarian cohort study.

Methods: In this non-interventional, cross-sectional retrospective study carried out in 11 Hungarian arthritis centres, we assessed high risk $(\geq 40 \%)$ of RRP in biologic-naive RA patients with active disease. In order to obtain a representative sample, patients were selected from each centre by a random technique. RRP was calculated according to the matrix model described by Vastesaeger et al. As a secondary endpoint, we compared methotrexate (MTX) responders vs non-responders with respect to RRP.

Results: We screened data of 1843 RA patients. Finally, data obtained from 1356 patients could be used for RRP prediction and MTX responsiveness. The mean age of patients was 55.5 years, $84.7 \%$ were women. The mean disease duration was 8.4 years. At the time of the assessment, mean CRP was 17.7 $\mathrm{mg} / \mathrm{l}$, RF was $139,3 \mathrm{lU} / \mathrm{ml}$, mean DAS28 was 5.00 and mean swollen joint count was 6.56. High risk $((\geq 40 \%)$ of RRP could be determined in $18.2 \%$ of patients. Among continuous variables other than those used for calculation of RRP risk, RA patients with the risk of RRP $>40 \%(n=247)$ had significantly lower age than those with $R R P<40 \%(n=1109)(53.33 \pm 12.31$ vs $56.02 \pm 13.50$ years; $p=0.001)$. With respect to binary variables, the risk of $\mathrm{RRP} \geq 40 \%$ was significantly associated 
with non-response to MTX (OR: 17.82), male gender (OR: 1.53), ACPA positivity (OR: 2.11), the presence of erosions (OR: 1.37) and current smoking (OR: 1.66). Binary logistic regression analysis revealed that MTX non-response (OR: 16.84), male gender (OR: 1.67) and ACPA positivity (OR: 2.18) were independent predictors of high-risk RRP ( $\geq 40 \%)$. With regards to MTX responsiveness, binary logistic regression analysis confirmed that both male gender (OR: 5.20) and the presence of erosions (OR: 7.98) were independent predictors of high RRP risk in the MTX responder subpopulation.

Conclusions: In the first bioloigc-naive Hungarian RA cohort assessed for RRP,
RRP occurs in almost one-fifth of the patients. These patients differ from others in various clinical and serological parameters. RRP has also been associated with non-response to MTX.

\section{References:}

[1] Vastesaeger N, Xu S, Aletaha D, St Clair EW, Smolen JS. A pilot risk model for the prediction of rapid radiographic progression in rheumatoid arthritis. Rheumatology (Oxford). 2009 Sep;48(9):1114-21.

Disclosure of Interest: None declared

DOI: 10.1136/annrheumdis-2017-eular.3199 